\title{
Stable: structural stability risk assessment
}

Serpetti, Matteo, Carlucci, Renzo, Di lorio, Alessio, Bozzano, Francesca, Antonielli, Benedetta, et al.

Matteo Serpetti, Renzo Carlucci, Alessio Di lorio, Francesca Bozzano, Benedetta Antonielli, Salvatore Martino, Betty Charalampopoulou, Christos Kontopoulos, Paris Fokaides, Petros Christou, Nikos Papadopoulos, Haris Saroglou, Stefano De Angeli, "Stable: structural stability risk assessment," Proc. SPIE 11524, Eighth International Conference on Remote Sensing and Geoinformation of the Environment (RSCy2020), 115240D (26 August 2020); doi: $10.1117 / 12.2571956$ 


\title{
Stable: STructural stABiLity risk assEssment
}

\author{
Matteo Serpetti ${ }^{\mathrm{a}}$, Renzo Carlucci ${ }^{\mathrm{a}}$, Alessio Di Iorio*a, Francesca Bozzano ${ }^{\mathrm{b}}$, Benedetta Antonielli ${ }^{\mathrm{b}}$, \\ Salvatore Martino $^{\mathrm{b}}$, Betty Charalampopoulou ${ }^{\mathrm{c}}$, Christos Kontopoulos $^{\mathrm{c}}$, Paris Fokaides ${ }^{\mathrm{d}}$, Petros \\ Christou $^{\mathrm{d}}$, Nikos Papadopoulos ${ }^{\mathrm{e}}$, Haris Saroglou ${ }^{\mathrm{f}}$, Stefano De Angeli ${ }^{\mathrm{g}}$ \\ ${ }^{\mathrm{a}}$ ALMA SISTEMI Srl, 4, Via dei Nasturzi, 00012 Guidonia Montecelio RM, Italy, ${ }^{\mathrm{b}} \mathrm{La}$ Sapienza \\ University, Piazzale Alldo Moro, 5, 00185 Roma RM, 'GEOSYSTEMS HELLA'S S.A, 88A, \\ Ginosati, Metamorfwsi, 11743 Athens, Greece, ${ }^{\mathrm{d}}$ Frederick University, 7, Frederickou Str., 1036, \\ Nicosia, Cyprus, ${ }^{e}$ Foundation for Research \& Technology Hellas (FORTH), Nikiforou Foka 130 \\ 74100 Rethymno, Crete, Greece, ${ }^{\mathrm{f}}$ National Technical University of Athens (NTUA), Zografou \\ Campus 9, Iroon Polytechniou str, 15780 Zografou, Athens, Greece, ${ }^{\mathrm{g}}$ Tuscia University, 4, Via Santa \\ Maria in Gradi, 01100 Viterbo VT.
}

\begin{abstract}
European cultural heritage $(\mathrm{CH})$ is at risk, threatened by environmental processes strengthened by climate change and anthropogenic pressure. In particular, the slow (landslides, subsidence) and seismic (earthquakes) movements of the soil have a strong impact on the structural stability of our cultural heritage $(\mathrm{CH})$. The actions to be carried out to protect and safeguard $\mathrm{CH}$ are in continuous development and this is where the STABLE (STructural stABiLity risk assEssment) project fits.
\end{abstract}

STABLE concerns the design and development of a thematic platform, which combines structural stability models, simulation and damage assessment tools, advanced remote sensing, in situ monitoring technologies, geotechnical and cadastral data sets with the WebGIS application for mapping and long-term monitoring of the $\mathrm{CH}$.

The thematic platform, which is the final objective of the project, will therefore support the authorities responsible for the conservation of cultural heritage in the design and implementation of policies for monitoring, preserving and safeguarding our heritage.

This will allow effective monitoring and management of $\mathrm{CH}$ to prevent or at least reduce the possible irreparable damages.

STABLE will coordinate existing skills and research in a synergistic plan of collaborations and staff exchanges to offer a complete transfer of knowledge and training to researchers in the specific area under study.

The development of the platform will be the strategy that scientists will have to follow to share and improve $\mathrm{CH}$ safeguard methods.

It will serve professionals to apply the most advanced technologies in their fields.

Keywords: Cultural Heritage, Cultural Memories, Remote Sensing, Civil Engineering, Risk map, Risk analysis

\section{INTRODUCTION}

STABLE (STructural stABiLity risk assEssment, 2018-2022, Horizon2020, MSCA - Marie Sklodowska Curie Actions RISE - Research and Innovation Staff Exchange - grant agreement n. 823966), has the goal of developing a digital platform to forecast earthquake damage to Historical City Centers in Europe combining different techniques and methodologies: structural stability models, earthquake simulation tools combined with geotechnical data, remote sensing and in situ monitoring technologies.

*adi@alma-sistemi.com, phone +393356317013, www.alma-sistemi.com

Eighth International Conference on Remote Sensing and Geoinformation of the Environment (RSCy2020), edited by

K. Themistocleous, G. Papadavid, S. Michaelides, V. Ambrosia, D. G. Hadjimitsis Proc. of SPIE Vol. 11524,

115240D · @ 2020 SPIE · CCC code: 0277-786X/20/\$21 · doi: 10.1117/12.2571956 
The STABLE team is composed by seven different partner from Italy (University "La Sapienza", Rome; University of La Tuscia, Viterbo), Greece (National Technical University and Geosystem Hellas from Athens and FORTH from Retymnio) and Cyprus (Frederick University and System Space Solution Ltd), with specific expertise, coordinated together by ALMA Sistemi Srl (Italian SME), with a plan of collaborations and staff exchanges in order to allow interdisciplinary research.

For STABLE were chosen emblematic case studies of buildings, in different country: a few blocks in the city center of Rieti for Italy, city blocks in Nauplion and the Lavrion area for Greece, and few buildings in the central area of Strovolos, district close to Nicosia for Cyprus.

Goal of the project is the definition of a risk modelling system with the integration of different data, from SAR satellite images to geological and geotechnical information, in order to create deformation soil maps. Everything are helpful to monitoring and verify the structural model of $\mathrm{CH}$ buildings and historical centers, which allow have a structural stability model of $\mathrm{CH}$ in different scenarios of seismic ground motion.

The risk maps will be generated from the classification of the values obtained in the final maps, result of the relation between the data described above, using a GIS system. GIS with data repository where will converge all the data used and produced in the project, in order to make public and interact the work done in the project through the construction of a web-GIS.

In the following figure, there is overall flow chart diagram of the of the project STABLE:

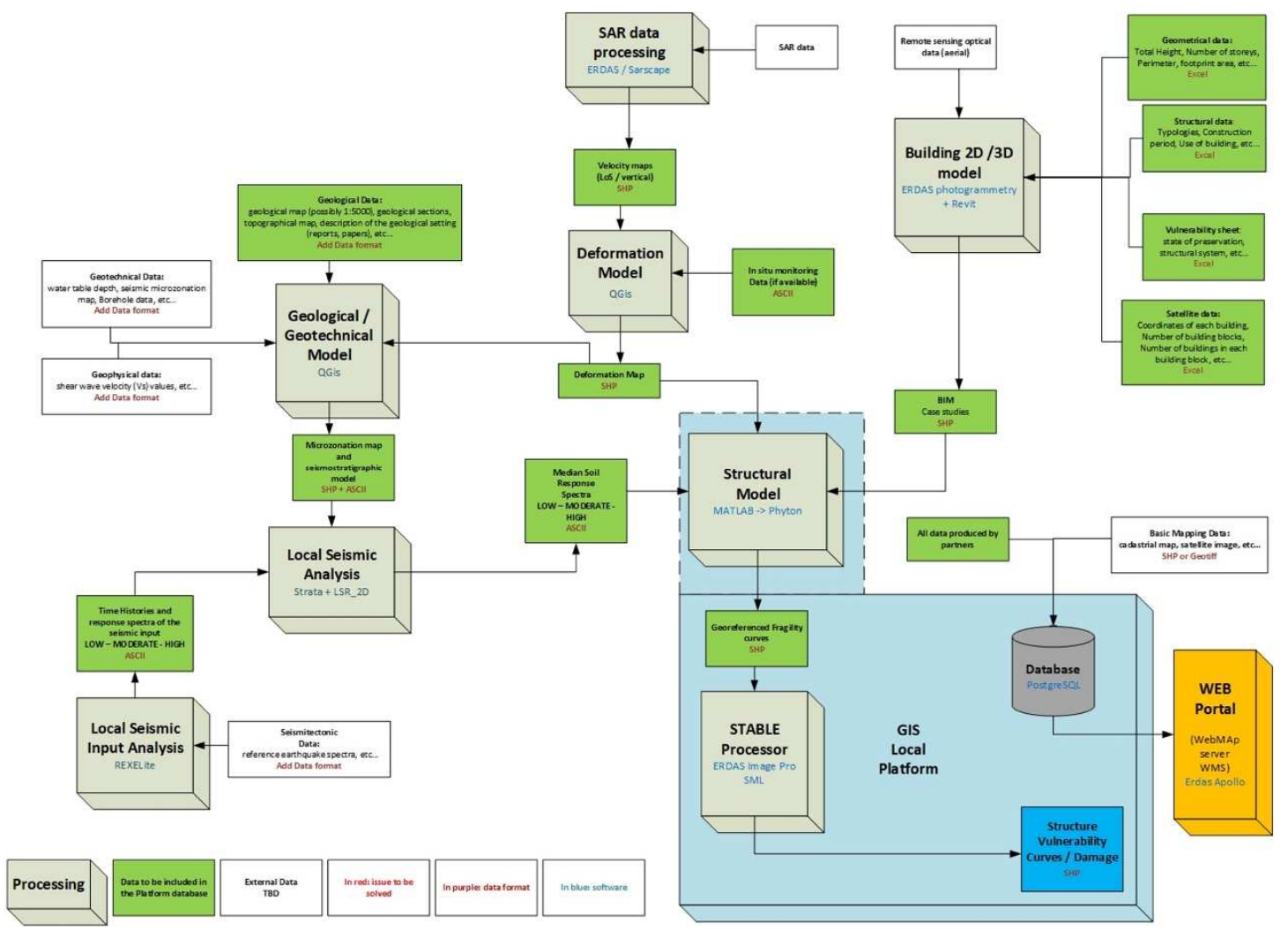

Figure 1. STABLE: flow chart of activities. In grey all the processor module for the different chain of data, coming from different sources. The final maps, blue, are shared through a webgis portal. 


\section{THE CONSTRUCTION OF THE MODEL}

\subsection{Geological and geotechnical model}

The first step of the STABLE workflow consists in constructing the engineering geological model of the different case study areas to provide a seismostratigraphic model of the subsoil for the subsequent local seismic response analysis.

In this regard, background information on local geological conditions and geophysical and engineering geological data produced by already-performed investigations have to be previously collected. These data include published papers and maps as well as any technical results from laboratory tests or on-site investigation, e.g. geological and engineering geological maps, stratigraphies from boreholes, soil parameter tests, geophysical investigation results, and so on. The interpretation of the collected data coupled with geological and geomorphological surveys on site as well as geomorphological remote surveys allows to provide a well-constrained engineering geological model of the subsoil for each case study.

Based on the reconstructed engineering geological model, seismic ambient noise will be recorded on several one-hour single-station measurement points in each study area, starting with a spacing of few tens of meters and, in case of unclear and/or variable results, densifying the grid point spacing. According to Nakamura (1989), the recorded time histories will be processed by the open access Geopsy software (www.geopsy.org) to carry out the Horizontal-to-Vertical Spectral Ratio (HVSR) analysis for evaluating the site resonance frequency $\left(\mathrm{f}_{0}\right)$, useful to calibrate the reconstructed engineering geological model as well as to validate the results of the subsequent local seismic response analysis.

The final output of the first STABLE workflow step consists in providing a seismic microzonation map for each case study, in which the study area is divided in different zones having similar subsoil setting and expected ground shaking in case of earthquake; for each zone, a seismostratigraphic model will be provided in terms of a seismostratigraphic reference column or a seismostratigraphic reference cross-section based on the geological complexity of the site.

\subsection{Local seismic analysis}

The second step of the STABLE workflow consists in modelling the local seismic response of the different zones previously defined in the engineering geological model of the different case study areas, in the aim of providing the expected ground seismic shaking in terms of soil response spectra.

The soil response spectra will be obtained by numerical approaches which simulate seismic waves propagation within the defined seismostratigraphic models. These numerical approaches will employ software based on equivalent-linear approach in the frequency domain, that assume a viscoelastic soil behavior, and which are able to simulate monodimensional (e.g. STRATA by Kottke and Rathje, 2008) or bi-dimensional (e.g. LRS2D by STACEC, www.stacec.com) seismic waves propagation.

The local seismic response will require the definition of three reference earthquakes for each case study to be used as inputs for the numerical simulations. Based on a probabilistic approach, the three reference earthquakes will be selected considering three different return periods, that represent three different levels of seismic hazard (i.e. low, moderate and high) and where the increasing of the return period indicates an earthquake having higher magnitude.

The final output of second STABLE workflow step consists in providing a soil response spectrum for each different zone defined in the microzonation map, that will be used as input for the structural model based on the location of the selected buildings.

\subsection{Deformation model}

The elaboration of the deformation model for each case study consists in the detection of possible deformation phenomena (such as subsidence, structural yielding, landslides, seismic-induced slope instabilities etc.), that can affect the buildings selected for the structural modelling. These local deformation phenomena could be taken into account in evaluating the structural response of the buildings to seismic shaking.

The main technique adopted for building the deformation model will be the satellite Synthetic Aperture Radar Interferometry (InSAR; Massonnet and Feigl, 1998; Hanssen, 2001), integrating the results with the geological and geotechnical data available in literature in order to analyze and understand the deformation processes eventually detected. 
InSAR can be considered the main satellite remote sensing technique used for the measurement of displacements of the Earth's surface. It is based on the comparison between different RADAR images acquired in different times over the same area (Differential SAR Interferometry).

The basic principle of multi-image or Advanced DInSAR (A-DInSAR) methodologies consists of the combination of information from a large number of radar images, allowing to derive the temporal evolution of displacements of objects on the ground during the time of interest.

This remote sensing technique will allow investigation in a broad zone and will provide a synoptic view of the study area with a very high measuring accuracy. This allows the detection of deformation phenomena over large areas otherwise not detectable.

The role of in-situ monitoring systems (already present at the selected studied areas) is being evaluated, according to the occurrence or lack of active monitoring systems already installed at the test sites.

InSAR results will allow to detect deformation phenomena that could be linked or not by cause-effect relationships with the building fractures (that are due to seismic shaking). For example, these deformation phenomena could be represented by subsidence or structural yielding, which could adversely affect the stability of a building.

The contribution that InSAR could provide for the assessment of the seismic vulnerability of cultural heritage buildings, is being sought and inferred through a literature survey (i.e. Del Soldato et al., 2019), and we infer that the building fragility curves in response to seismic shaking should be modified in order to take the occurrence of independent deformation phenomena (retrieved by InSAR) into consideration.

\subsection{Structural model}

The goals of the study are to investigate the vulnerability of the built environment and to combine the results with hazard scenarios as the first fundamental step in the seismic risk mitigation process. The two key elements of a vulnerability analysis are the capacity (strength and deformation) of a structure and the seismic demand. The results are vulnerability functions expressing the expected damage of the structure as a function of the seismic input. Corresponding fragility curves will be determined, expressing the probability of a structure belonging to a certain class of reaching or exceeding a particular damage grade given a deterministic estimate of the spectral displacement of the expected hazard.

The expected risk is determined according to the following expression:

$$
\text { Risk }=f(\text { Hazard, Vulnerability })
$$

where:

Hazard: as defined for the seismicity of the region and the accepted probability of exceedance

Vulnerability: as expressed by the defined capacity of the structure as described in the following

The $f$ function depending from the various methods for the assessment of the vulnerability of structures an hazard of soil. The type of method chosen depends on the objective of the assessment but also on the availability of data and technology. In general, a vulnerability function is a relationship which defines the expected damage for a structure or a class of structures as a function of the ground motion (Figure 2). The two key elements of a vulnerability analysis are the capacity of the structure and the seismic demand. In order to estimate the damage $D$, the ability of the structure to resist constraints (capacity of the structure) must be compared with the constraints on the structure due to the earthquake ground motion (seismic demand). 


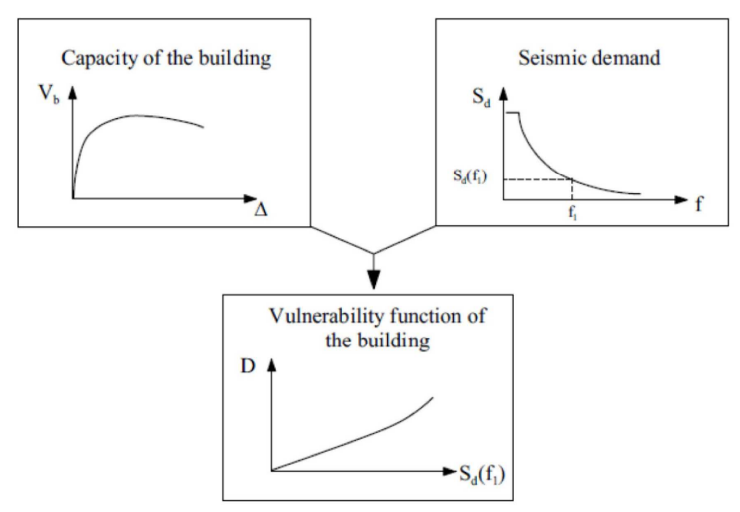

Figure 1. Principle of a Vulnerability function

In earthquake engineering the capacity of a structure to resist seismic action is presented by a capacity curve which is defined as the base shear, $V b$, acting on the structure as a function of the horizontal displacement at the top of the structure $\Delta$, also often referred to as a pushover curve. The shear capacity of the structure refers to the maximum base shear the structure can sustain $\mathrm{Vbm}$ and the displacement capacity refers to the ultimate displacement at the top of the structure $\Delta b u$.

To express the seismic demand, until very recently, the "intensity" was used nearly exclusively. This is a descriptive parameter of an earthquake based on observations of the effects of the earthquake on the environment. It has the advantage that historical data on earthquakes are available. However, information on the real ground movement is lost and empirical relationships between intensity and peak ground acceleration vary a lot. Some methods use the peak ground acceleration as the parameter defining the earthquake. However, in that case, not only the information on the duration of the earthquake is lost, but also the information on the frequency content. Thus, a better parameter is the spectral acceleration $S a$, or the spectral displacement $S d$.

The estimation of damage probability will be performed by means of a simplified mechanical methodology. Initially the required input parameters will be collected including:

- Structural data (typology, construction period, use of building, post-earthquake damage data, detection of different construction phases, etc)

- Geometrical data (total height, number of storeys, perimeter, footprint area, average bearing wall thickness for masonry structures, Plan view at least of the ground-floor, etc)

- Satellite data (coordinates of each building, number of building blocks, number of buildings in each building block)

-Vulnerability data (estimation of vulnerability by rapid assessment methods)

In the following the dominant eigenperiod will be determined for every structure and the capacity curve will be defined relating the base shear and the relevant deformation. The main damage limit states in terms of displacement thresholds $S d, k$ will be identified on the capacity curve as a function of the yielding and of the ultimate displacements. For selective case-study buildings both the capacity curve and the exact displacements related to specific damage states will be derived through sophisticated analysis.

By combining the capacity curve and the seismic hazard the target displacement $S d *$ will be defined. Finally the fragility curves, giving the probability that the damage is equal to or higher than a certain state $D k$, will be obtained as a function of the target displacement $S d *$ and of the defined displacement thresholds $S d, k$ by the use of a probability theory.

All the calculation process will be in MATLAB, a programming platform designed to allow expression of computational mathematics. This will allow us to analyze data, develop algorithms and create models and applications, with the final aim to define the capacity curve and the exact displacements related to specific damage states, which may be derived through sophisticated analysis for a selective case-study building. 


\subsection{GIS data preparation from 3D digitization process}

The results of the GIS data preparation for the structural model deriving from the 3D stereo digitization process come in different Level of Details (LoD) but also in a format not easily processed in the next stages of the project.

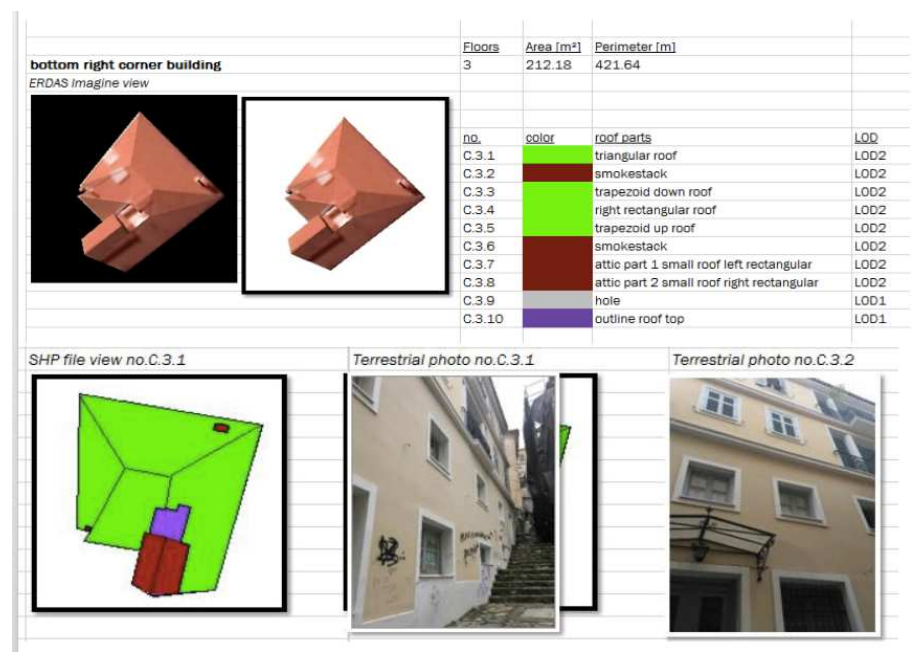

Figure 3. Different LoD of the 3D stereo digitization process

A pipeline (Figure 4) of converting the 3D vector to a 2D building footprint and 3D information into attributes of each unit has been generated for this purpose.

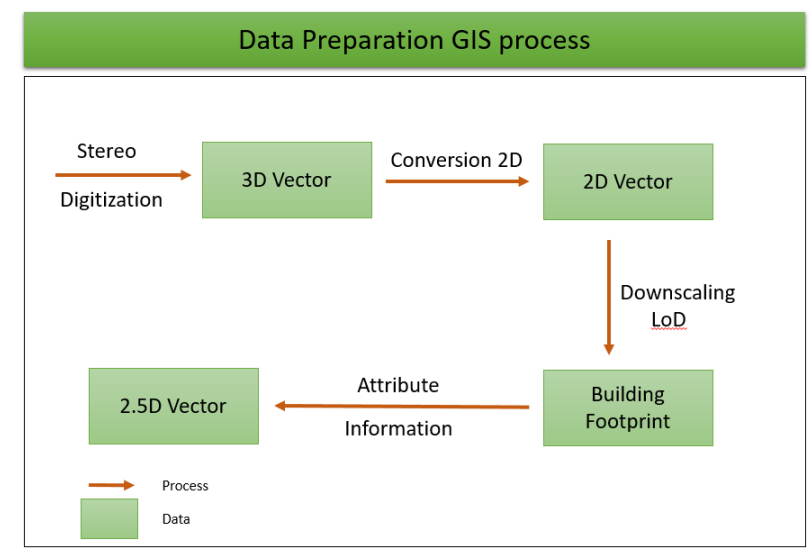

Figure 4. Data Preparation of GIS process workflow

This workflow consumes the digitized 3D surfaces vector files and at first converts all features to 2D. The elevation information is not lost but transposed as an attribute information for each feature unit. Then, all polygon features depicting the same building are merged together to a downscaled unified building footprint polygon. Finally, all necessary information required for the Structural Model analysis are filled into the corresponding attribute fields of each building unit. 


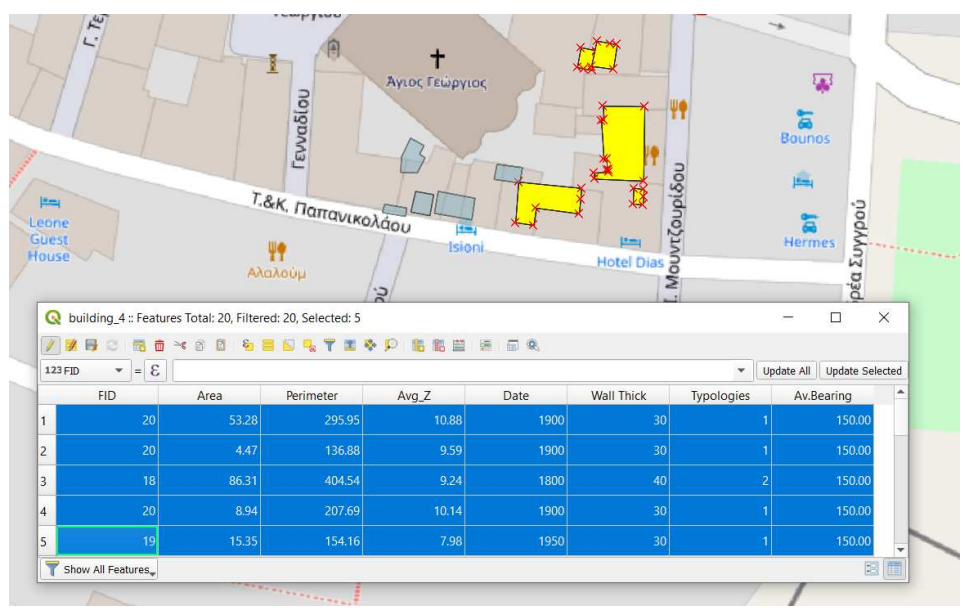

Figure 5. The 2D building footprints with all attribute information

\section{STABLE GIS PLATFORM}

The STABLE project Local Platform will make use of GIS and Remote Sensing Software and Techniques in order to better deal with all the datasets, deriving from the previous stages of the project.

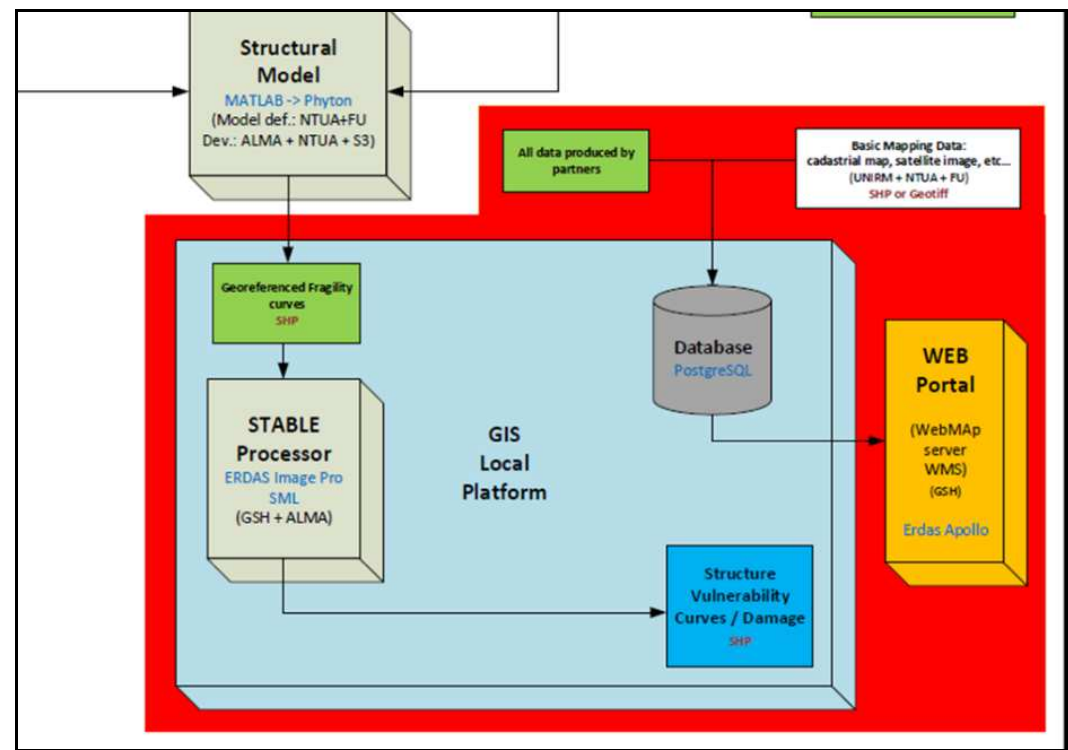

Figure 6. The STABLE GIS Local platform

The GIS Local platform as illustrated in in the above schema (Figure 6), will act as the STABLE data repository including:

- The STABLE database

- The output data of the Structural Model processor 
In terms of implementation tools, the STABLE consortium has started the analysis of the possible platforms that best fit the requirements and the future expectations. In this moment the HEXAGON Geospatial's Producer Suite is under evaluation like other similar OpenSource tools.

HEXAGON package includes numerous desktop-based solutions for GIS, remote sensing and photogrammetric applications that could fill all STABLE processing and data manipulation needs.

More specifically, and concerning the processing of the Structural Model processor outputs, automated workflows are used for the conversion of the Georeferenced Fragility curves to actual classified Structural Vulnerability features.

The basic subject of analysis is a polygon feature covering each building of study. For the total sum of buildings, a classification process should be implemented in order for the final Structural Vulnerability map to be exported. Essentially, each building/feature is classified according it's assigned fragility value from the previous Structural Model processor step.

An automated spatial workflow is required to build a flow chart that contains operators strung together logically to produce output results.

Hexagon's ERDAS IMAGINE desktop solution can produce automated workflows through Spatial Model Language (SML) that allows such a development in a way that all case study buildings are classified in respect with their fragility index.

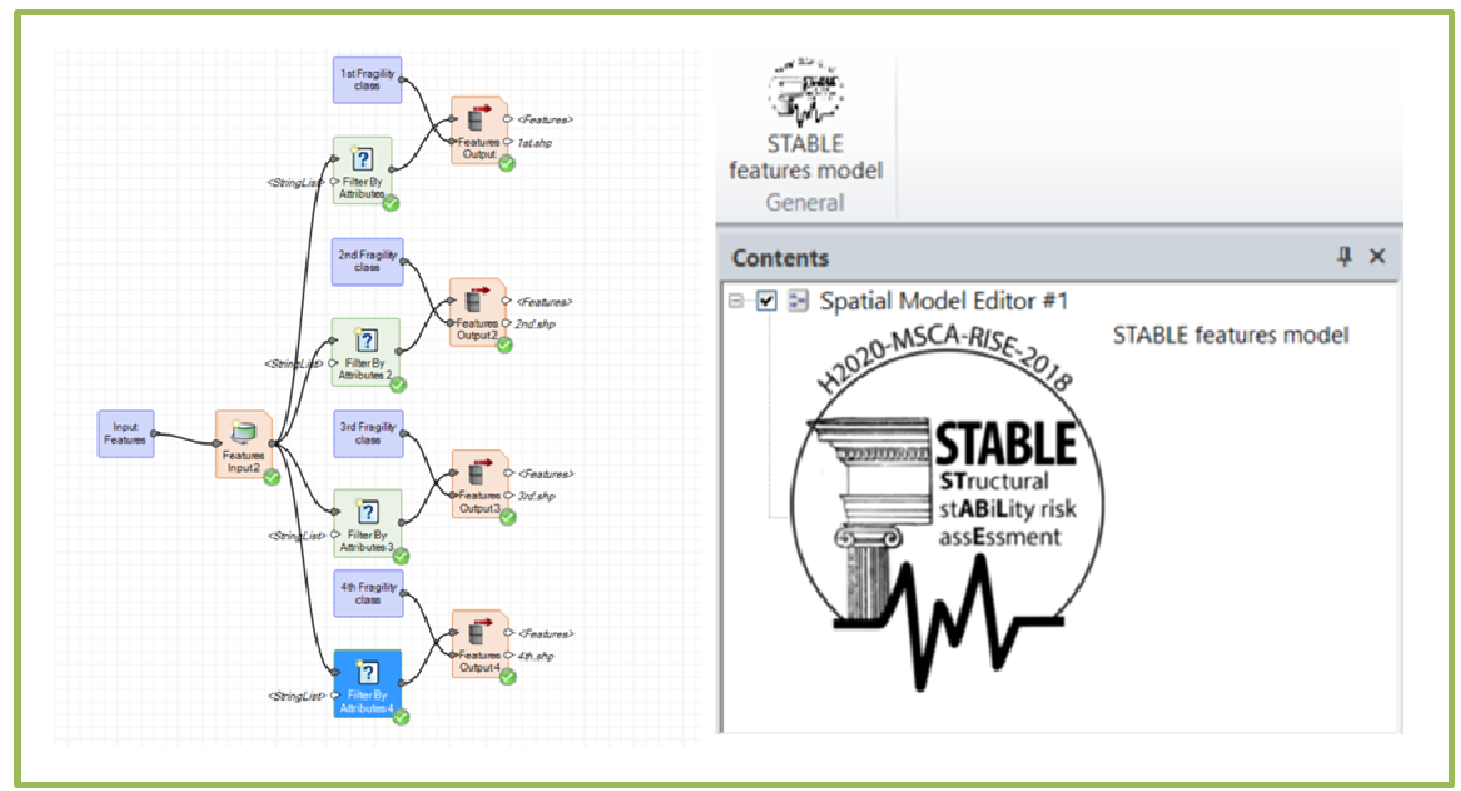

Figure 7. Depiction of the Spatial Model architecture and Operator

Above, a demo Spatial Model workflow is shown, as built for the STABLE project purposes and to this direction: on the right the application button and Spatial Model as shown in the contents workspace in Erdas Imagine 2018. On the left the contents and architecture of the developed Model.

As illustrated in Figure 7 the Automated process through the SML operator takes as input building polygons in a shapefile format, as deriving from the Structural Model analysis, and extracts different classes of these building according to their vulnerability level. 


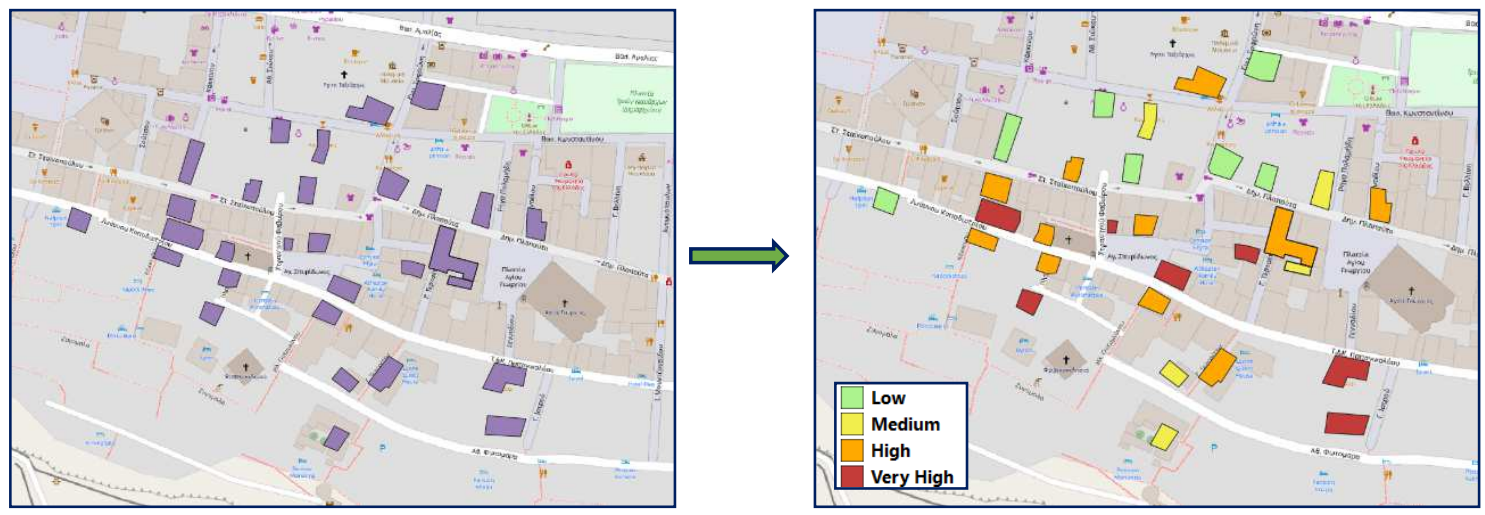

Figure 8. Result of the Spatial Model for building vulnerability classification

\section{ACTUAL ACHIEVEMENTS - PROBLEMS AND SOLUTIONS}

The project is based on the application of the simplified structural stability model to the whole area of the city center under analysis. The simulation of different earthquake scenarios, also considering the geological information available, and the response of the structures involved in the scenario will provide detailed damage maps of the area at building level, enabling preparedness to the seismic events. Public authorities, Urban Planners and Cultural Heritage responsible will have the capability to address preventive maintenance and consolidation of the structures that will result most damaged by future earthquakes.

This approach will have the twofold objective to drastically reduce the reconstruction and restoration costs as well as reduce the death toll associated with the seismic activity.

The project has been running for almost one year and half mostly spent in the definition of the overall system and will last until October 2022. Unfortunately, the recent Covid-19 outbreak is already jeopardizing the project activities and a delay of 6 months has been taken into account. We are in constant connection with the Research Executive Agency of the European Union to minimize the impact of the emergency to the specific research.

\section{References}

[1] Del Soldato M., Solari L., Poggi F., Raspini F., Tomás R., Fanti R., Casagli N. (2019). Landslide-Induced Damage Probability Estimation Coupling InSAR and Field Survey Data by Fragility Curves. Remote Sens., 11, 1486, doi:10.3390/rs11121486.

[2] Hanssen, Ramon F. (2001). Radar Interferometry: Data Interpretation and Error Analysis, Kluwer Academic, ISBN 9780792369455.

[3] Kottke A.R., Rathje E.M. (2008) Technical manual for Strata, PEER Report 2008/10, Pacific Earthquake Engineering Research Center College of Engineering, University of California, Berkeley.

[4] Massonnet, D., Feigl, K. L. (1998). Radar interferometry and its application to changes in the earth's surface, Rev. Geophys.36(4): 441-500, Bibcode: 1998 RvGeo. 36.441M, doi: 10.1029/97RG03139.

[5] Nakamura Y. (1989) A method for dynamic characteristics estimation of subsurface using microtremor on the ground surface. Quarterly Report of Railway Technical Research Institute (RTRI), 30(1), 25-33 